\title{
Voltage Control of Transmission System Using Static Var Compensator
}

\author{
Sandesh Jain \\ Samrat Ashok Technological Institute \\ Vidisha, Madhya Pradesh, \\ India
}

\author{
Shivendra Singh Thakur \\ Samrat Ashok Technological Institute \\ Vidisha, Madhya Pradesh, \\ India
}

\begin{abstract}
This paper will discuss how static Var compensator successfully been applied to control transmission system. The voltage level of the system changes when there is a change in load and the drop in load voltage lead to demand for the reactive power. Static Var Compensator is basically a shunt connected Static Var Generator whose output is controlled by adjust the value of capacitive or inductive current. One of the reasons for installing the Static Var Compensator to improve the voltage profile and increases the system lodability. When system voltage is low it generates the reactive power. When the system voltage is high it absorbs the reactive power. FACTS are technologies that increase flexibility of transmission system, control of power flow and increases transmission capacity of the system. In this paper FACT controller such as Static Var Compensator are used to maintain the voltage within limit. Simulation will be provided by using MATLAB.
\end{abstract}

Keywords: Voltage Control, FACT, Static Var Compensator, Performance, VAR planning, MATLAB/SIMULINK

\section{INTRODUCTION}

In presently, power system are large, complex and interconnected system, which consist of thousand of buses and hundreds of generator. In presently electric power system create a need of flexibility, reliability, accuracy and fast dynamic response. Flexible alternating current transmission system is new device that are capable of increase transmission capacity, increase lodability, stability of the transmission system. Static Var Compensator is thyristor based controller that provides rapid voltage control. The situation has occurred increase transient, oscillatory and voltage instability, which are now these problem can be rectified by using Static Var Compensator. Voltage instability is the cause of voltage collapse. The only way to save the system of voltage collapse through control reactive power. Various FACTS device are connected in the transmission line to inject and absorb the reactive power. When it will absorb the reactive power TCR are connected in the transmission line. When it will inject the reactive power TSC are connected in the transmission line.

\section{The Thyristor switched capacitor (TSC)-}

It consists of a capacitor, a bidirectional thyristor valve, and a relatively small surge current limiting reactor. This reactor is needed primarily to limit the surge current in the thyristor valve under abnormal operating. When a capacitor is switched into a sinusoidal voltage source, a large current surge flows through the capacitor if the initial voltage across the capacitor is different than the supply voltage at the instant of switching. The current through the capacitor will be finite (corresponding to the steady state value) if the initial capacitor voltage is equal to the supply voltage at the instant of switching. However the rate of change of current will be very high, beyond the rating of the thyristor devices (acting as switches). To limit the it is necessary to insert a reactor in series with the capacitor.

\section{The Thyristor controlled reactor (TCR)-}

It consists of a bidirectional thyristor valve, and a current limiting reactor is connected in series. This reactor is needed to limit the surge current. Under high voltage conditions, the SVC will be at its inductive limit and the TCR current may exceed its rated value. To protect the thyristor valves used in TCR, it is necessary to limit the current through it by phase control. To avoid interaction with voltage regulator function, a time delay is introduced (of the order of $100 \mathrm{~ms}$ ). The over current limiter takes into account the short-term overload capability of the TCR.Series Capacitors have been used in long distance EHV transmission lines for increasing power transfer. The use of series capacitors is generally the most economic solution for enhancing power flow. However, the problem of SSR has deterred system planners from going in a big way for series compensation. While the use of shunt capacitors doesn't have the problem of SSR, they have drawbacks of their effectiveness being dependent largely on their location. Even when a shunt capacitor is located at the midpoint of a long line, it requires much larger rating to achieve the same level of increase in power transfer as a series capacitor.

\section{STATIC VAR COMPENSATOR}

The Static Var Compensator (SVC), a first generation FACTS controller is taken up for study. It is a variable impedance device where the current through a reactor is controlled using back to back connected thyristor valves. The application of thyristor valve technology to SVC is an of shoot of the developments in HVDC technology. The major difference is that thyristor valves used in SVC are rated for lower voltages as the SVC is connected to an EHV line through a step down transformer or connected to the tertiary winding of a power transformer. The application of SVC was initially for load compensation of fast changing loads such as steel mills and arc furnaces. Here the objective is to provide dynamic power factor improvement and also balance the currents on the 


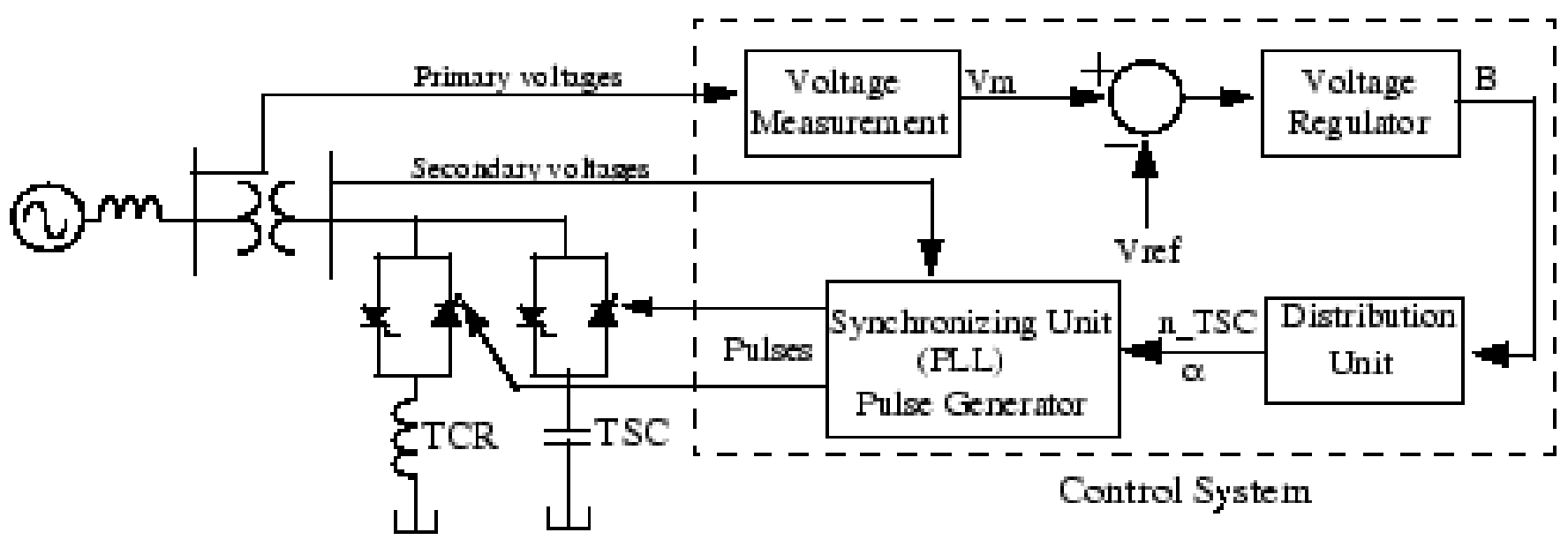

Figure 1.

Compensators commenced in the late seventies. Here the objectives are:

1. Increase power transfer in long lines

2. Improve stability with fast acting voltage regulation

3. Damp low frequency oscillations due to swing (rotor) modes

4. Damp sub synchronous frequency oscillations due to torsional modes

\section{Control dynamic over voltages}

\section{SVC CONTROLLER}

SVC Controller incorporating voltage regulator. This shows that both voltage (VSV C) and current (ISV C) signals are obtained from potential and current transformers and then rectified. The AC filter is basically a notch filter to eliminate the signal component of frequency corresponding to the parallel resonance in the system viewed from the SVC bus. The line capacitance (in parallel with SVC capacitance) can result in parallel resonance with the line inductance. The SVC voltage regulator has a tendency to destabilize this resonant mode of oscillation and the notch filter is aimed at overcoming this problem. As a matter of fact, any parallel resonance mode (of frequency below second harmonic) can have adverse interaction with SVC voltage regulator. If series capacitors are used along with SVC, then they can cause parallel resonance with a neighboring shunt reactor. If the second (parallel resonance) mode has a lower frequency (say below $20 \mathrm{~Hz}$ ), a high pass filter in addition to the Notch filter has been suggested.

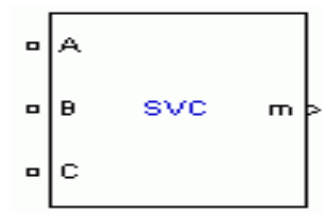

Figure 2

\section{SVC V-I CHARACTERISTIC}

The SVC can be operated in two different modes: In voltage regulation mode and in var control mode (the SVC Susceptance is kept constant) when the SVC is operated in voltage regulation mode, it implements the following V-I Characteristic. As long as the SVC susceptance B stays within the maximum and minimum susceptance values imposed by the total reactive power of capacitor banks (Bcmax) and reactor banks (Blmax), the voltage is regulated at the reference voltage Vref. However, a voltage droop is normally used (usually between $1 \%$ and $4 \%$ at maximum reactive power output), and the V-I characteristic has the slope indicated.

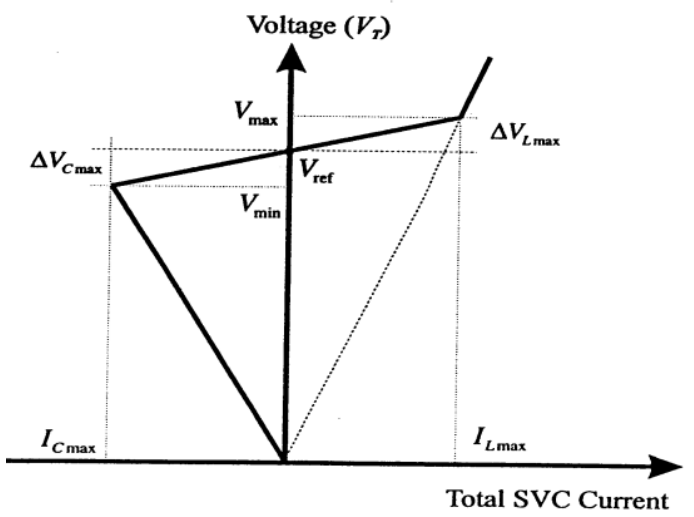

Figure 3

The voltage at which SVC neither absorbs nor generates reactive power is the reference voltage (Vref).In practice this voltage can be adjusted within the typical range of $\pm 10 \%$. The slope of the characteristics reflects a Change in voltage with compensator current and, therefore can be considered as slope reactance, resulting the SVC Response to the voltage variation. Then terminal voltage is given by

$$
\begin{aligned}
& \text { VSV C }=\text { Vref }+ \text { XsISV C } \\
& \text { ISV C }=\text { ¡BSV CVSV C }
\end{aligned}
$$




\section{SVC OPERATING WITHIN CONTROL RANGE}

The control range of a SVC is defined as, Imin < ISVC < Imax and $V \min <\mathrm{V}<\mathrm{Vmax}$. In this range, the $\mathrm{SVC}$ is represented as $\mathrm{PV}$-node at an auxiliary bus with $\mathrm{P}=0$ and $\mathrm{V}=$ Vref. Reactance XSL equivalent to the slope of the V-I characteristics is added between the auxiliary node and node of coupling to the system as shown in Fig. 3. The node at the point of common coupling is a $\mathrm{PQ}$ node with $\mathrm{P}=0$ and $\mathrm{Q}=0$.

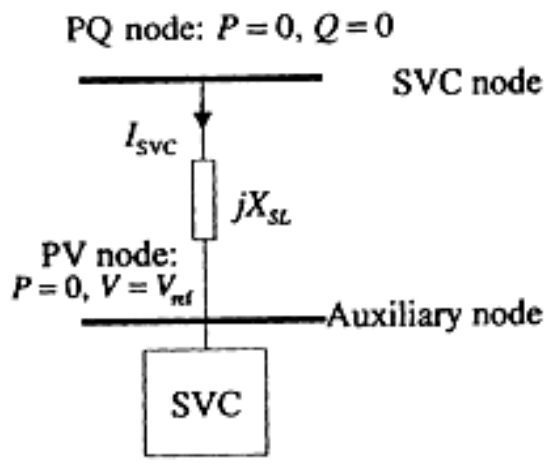

Figure 4

A static var compensator (SVC) is used to regulate voltage on a $33 \mathrm{kV}, 3 \times 50$ MVA system. When system voltage is low the SVC generates reactive power (SVC capacitive). When system voltage is high it absorbs reactive power (SVC inductive). The SVC is rated+50 Mvar capacitive and 25 Mvar inductive. The Static Var Compensator block is a Phasor model representing the SVC static and dynamic characteristics at the system fundamental frequency. The SVC is set in voltage regulation mode with a reference voltage Vref $=1.0 \mathrm{pu}$. The voltage droop is $0.03 \mathrm{p} . \mathrm{u}, 50 \mathrm{MVA}$, so that the voltage varies from 0.97 p.u to 1.015 p.u when the SVC current goes from fully capacitive to fully inductive. By simulating the SVC V-I characteristic curve is obtained. Then, the actual SVC positive-sequence voltage (V1) and susceptance (B1) can be measured with system parameters

$$
\begin{aligned}
& \mathrm{Ki}=200 \\
& \mathrm{Xn}=0.0667 \mathrm{pu} / 50 \mathrm{MVA} \\
& \mathrm{Xs}=0.03 \mathrm{pu} / 50 \mathrm{MVA} \\
& \mathrm{T}=0.0345 \mathrm{~s}
\end{aligned}
$$

The voltage/current characteristic of the compensator at the 33 $\mathrm{kV}$ bus is shown in Fig. 8. The slope of the control range is nominally $3 \%$. This means that a voltage change of $-3 \%$ produces the rated capacitive reactive power of $50 \mathrm{MV}$ ar. For a linear voltage-current characteristic, a voltage changes of $+3 \%$ produces an inductive reactive power of $50 \mathrm{MVar}$.

\section{CONCLUSION}

The proposed technique is applied to a simple power system. It is observed that power increases in the network and control the Bus voltage. Bus voltages of the network also improve. Stability analysis of the system after experiencing fault as well as consequent fault clearance by time domain analysis has also been performed and satisfactory results are obtained.

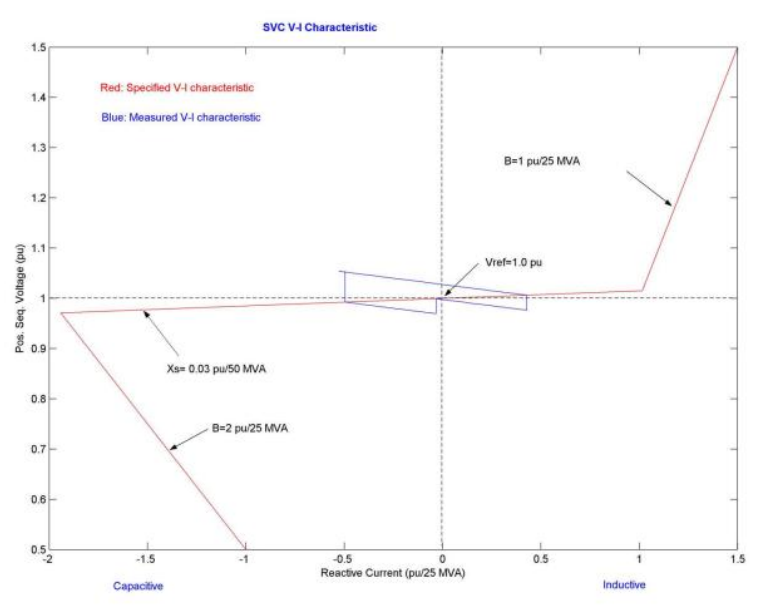

Figure 5

\section{REFERENCES}

[1] Md. Nazmus Sahadat, Real Power Transfer Capability Enhancement of Transmission Lines Using SVC, IEEE, (2011).

[2] A. H. M. A. Rahim, Voltage Stability Control of a Wind Generation System, IEEE(2010).

[3] Guizhen Tian, Power Quality and Transient Stability Improvement of Wind Farm with Fixed-Speed Induction Generators Using a STATCOM, IEEE (2010).

[4] Miller TJ Reactive power Control in Electric Systems. John Willey \& Sons (1982).

[5] K. R. Padiyar, FACTS CONTROLLERS IN POWER TRANSMISSION AND DISTRIBUTION, NEW AGE INTERNATIONAL (P) LIMITED, PUBLISHERS(2007). 